\title{
ROLE OF HIGHER SCHOOL IN FORMATION OF INNOVATIVE POTENTIAL OF REGION AS ELEMENT OF SUSTAINABLE DEVELOPMENT OF SHIPPING CLUSTER
}

\author{
Osipova Elena \\ Higher School of Economy, Management and Law \\ Northern (Arctic) Federal University named after M.V. \\ Lomonosov \\ Arkhangelsk, Russia \\ e.e.osipova@narfu.ru
}

\author{
Shirikhina Elena \\ Higher School of Economy, Management and Law \\ Northern (Arctic) Federal University named after M.V. \\ Lomonosov \\ Arkhangelsk, Russia \\ e.shirihina@narfu.ru
}

\begin{abstract}
When all sectors of the Russian economy turn into a high-tech production model, which is aggravated by the unfinished industrial modernization, there is a necessity to execute roles and responsibilities for training specialists with high qualification skills and competencies which allow ones to work in an innovative environment. The Northern (Arctic) Federal University assumes the mission to ensure innovative development of Arkhangelsk region with high-level human resources. The article describes economic situation in the Russian North, in particular, in Arkhangelsk region, prospects of its development, potential demanded by this development is analyzed and role of higher school in this process is defined. The article discusses current issues and challenges of sustainable development of the shipbuilding cluster of the region as a center of innovative economy. Also the negative issues, associated with development of shipbuilding cluster enterprises in the times of perestroika, the lack of innovative ideas are reflected here. An explanation of sustainable development of shipbuilding enterprises as the keystone of monocity development, as well as the role of higher school as an innovative potential, is given. The main landmarks of an economic, social and environmental performance complex as factors of sustainable development of enterprises and innovative economy, taking into account an influence of higher education on industry, are highlighted.
\end{abstract}

Keywords - innovative potential, higher education, shipbuilding cluster, sustainable development

\section{INTRODUCTION}

All modern countries focus their efforts on socio-economic development, both in the national and global context.

It is obvious that the basis for economic growth is the status of innovative component, namely dynamics and the level of its development.

It is especially important to emphasize the fact that human potential of any system is its value that cannot be underestimated.

Now the economic situation in the world, in particular, in Russia is such that there is a rise in unemployment. According to Rosstat (Russian Statistics Agency), in 2015, the unemployment rate was around $5.6 \%$ of the economically active population and the number of unemployed reached 4.3 million. The unemployment rate for 2016 was $5.8 \%$, and the number of unemployed was 4.4 million people, so, there is a constant tendency to increase this indicator.

Despite the fact that there is a kind of oversupply of labor resources, yet in order to get out of the crisis, country needs human resources of a much higher level. It is a requirement of a new innovation system.

A supplier of human resources of such level is designed to be exactly the higher school. Therefore, it can be argued that higher education is a major subsystem in formation of innovative potential of a country and a region.

Arkhangelsk region is the largest subject of the Federation in the European North of Russia. The region also includes the Nenets Autonomous district and the Arctic archipelagos of Novaya Zemlya and Franz Josef Land. The shores of Arkhangelsk region are washed by three seas of the Arctic ocean: the White, Barents and Kara seas. The population includes 1173763 people living in the area of 589913 square kilometers.

Thus, the area of Arkhangelsk region is comparable with territories of the major European States such as Ukraine, Spain, France. But the density of population is 1.99 persons per square kilometer.

Nature has generously endowed the region with its riches. In the depths of Pomorye, there are large deposits of bauxite, copper, diamonds, oil, gas and other minerals. So, the Lomonosov diamond field is the largest in the world.

Significant oil and gas fields were discovered on the shelf of the White and Kara seas.

The traditional industry of the Russian North is the forest industry. The largest in Russian Northwest enterprises - 
Arkhangelsk and Kotlas Pulp-and-Paper Mills - are directly related to the regional forest complex.

Another traditional and oldest sector of the economy of Arkhangelsk region is fishing.

The only Europe's cosmodrome "Plesetsk" is located in Arkhangelsk region.

Agriculture of the region is represented by several complexes involved in production of dairy products, in growing potatoes, beets, carrots.

Tourism develops in Arkhangelsk region significantly. Its peculiarities are due to the climatic and geographical conditions of the region. In particular, these are adventure and extreme tourism, hunting and fishing, cruise and events tourism, business and educational tourism [13].

The region's geographical location provides a sound foundation for international cooperation in the sphere of economy, education, culture and sports with countries in Barents-Arctic region.

Considerable remoteness from the center of Russia is balanced by developed transport infrastructure: air and rail service, a federal highway linking Pomorye and other regions.

The center for nuclear shipbuilding is located $35 \mathrm{~km}$ from Arkhangelsk, in the city of Severodvinsk on the White Sea. These are such enterprises of the shipbuilding cluster as JSC "PO "Sevmash" (shipbuilding and machinery), JSC "CS "Zvezdochka" (shiprepair, shipbuilding, and machinery), JSC "SPO "Arctic" (installation and commissioning of electrical equipment), "Polar Star" Plant (instrument engineering).

All above-mentioned indicates the enormous economic potential of Arkhangelsk region. Effectively used economic potential will enable Arkhangelsk region to provide jobs and welfare for population of the region, to improve education, $t$ health indicators and to increase life expectancy in the region.

The higher education in Russia plays an essential role in achievement of high indicators of sustainable development at the national and macroeconomic level.

Modern socio-economic conditions have higher requirements for training of specialists in various sectors of economy, for quality of their training, for competence and professionalism of higher school teachers.

But it is impossible to have a good specialist as long as problems of higher school are not solved; still there is no consistency and systematic approach in solution of these problems.

Lack of specific indicators to measure performance of higher education institutions affects negatively modernization of the higher school, and therefore, training of specialists for the innovation economy. The entire strategic management of the University should be based on a holistic, balanced system of indicators that characterize actual results of higher professional education activities.

Integration of modern information and communication technologies in educational process helps to modernize higher education.
Russian higher education should refer to experience of foreign countries where leading positions take academic sectors at the stage of scientific development. Thus, there is a clear connection of education, science, production, business and societal needs.

So, taking for granted the statement that innovation activities play an important role for small and medium businesses, it can be assumed that cooperation of these companies and universities will be beneficial to both parties. For example, in research, small and medium-sized firms in the United States, Western Europe and Japan are always created next to University centers and rent their space and equipment. So, about 3 thousand such enterprises located next to Stanford University (USA) are employing about 190 thousand people. This is an excellent base for future professionals in application of their knowledge and skills.

Also place of teaching staff of university deserves special attention in a process of modernization of higher education and economy in general. Teaching staff satisfaction with its position, working conditions, salary, status in university, participation in research activities plays an important role in formation of an innovative teacher and a student - future participant of economic relations of a new form.

Being an industrialized region and, at the same time, a strong educational and training center with convenient transport infrastructure, Arkhangelsk region has the purpose of intensive innovative development and international cooperation in the Arctic. So it is quite naturally to prepare here highly qualified personnel for all sectors of economy.

New forms, new approaches of this process are in close relationship of employers, educational institutions (NArFU), practice-oriented education. Expansion of network of laboratories and research centers at the base of University, active participation of both teachers and students in research activities, especially in applied research of practice oriented nature are also a part of innovative process.

Enterprises of shipbuilding cluster have production capacity and trained personnel of engineers and workers to build offshore platforms, propulsion systems and their components (propellers of all types, controllable pitch propellers), special ships, nuclear-powered icebreakers and special naval equipment for use in high latitudes (the first iceresistant oil platform and other special technique of dual purpose, constructed in Severodvinsk work already in the Arctic).

There is a strong scientific and educational base for properly functioning of cluster, where the main supplier of innovation, in addition to the Northern (Arctic) Federal University, is the Ural branch of the Russian Academy of Sciences. Moreover, cluster has its own design bureau "Onega" and "Rubin-Sever".

Special attention in a program of development of shipbuilding cluster is paid to improving training and retraining system. The center of existing educational potential of Arkhangelsk region is the Northern (Arctic) Federal University. A multilevel system of personnel training for shipbuilding and ship repair industry runs right now. 
It should not be forgotten that such vital aspects as support of small and medium business, formation of modern housing, transport, energy and educational infrastructure are included in a program of shipbuilding cluster development. This implies new jobs, advanced technology, filling up the budgets.

The University should train a new person - an innovative person, who seamlessly integrates into innovative process, will be part of this powerful system. Synergy of all components will bring the region and the country in general to a new level of socio-economic development.

Obviously, the first task of the higher school in modern conditions and in innovative development of the country is formation of an innovative personality type, which in turn will be the basis for formation of innovative potential of the region, including sustainable development of shipbuilding cluster, the keystone of economic growth and social stability in the Russian North and the country as a whole.

It should be remembered that innovation should be understood as use of scientific and technical knowledge in an innovation, which is associated with its market implementation. This fact makes innovation different from traditional forms of scientific and technical developments used in manufacturing and in economy. Problems and need for the revival and further development of an innovative sphere in Russia are crucial in a context of modern challenges, facing economy in a process of transition to sustainable development of real sector of economy, and, in particular, shipbuilding cluster. [1]

One of the most important requirements of the modern time is innovative nature of regional economy development. Innovations become the major condition of economic growth and development. Ensuring a necessary level of innovative activity in economy of the region is a key economic issue for the success of its development. The need for active use of innovation for all participants of the market economy is the main distinctive feature of the present time. In case of weakening or extinction of this field, it can be argued that it is an alarming signal not only for businesses but also for economy of any country and the world in general [5].

A decline in defense spending began in Russia in the late 80 -ies. A restructuring or a reduction of a part of defense industry became necessary, i.e. carrying out conversion, which had a negative impact on innovative development of not only current shipbuilding cluster, but the region as a whole.

In connection with a sharp decline in government orders, military industry began to experience an acute crisis. Actions, aimed at a conversion of production, entailed a reduction of personnel. Therefore, a process of conversion of defense industry generated a range of social problems: growing number of unemployed; need to provide retraining and employment for staff, losing jobs during conversion; to ensure its social security, rotation of specialists, based on their qualifications, personality, experience and desire.

Most of these problems affect monocities, where close links are between functioning of municipal economy and an enterprise. They are large enough to affect all major aspects of city life, i.e. the forming enterprise. Severodvinsk, the center of nuclear shipbuilding, belongs to such group of cities.
Conversion of military-industrial complex is not only a change in proportions between production of arms and military equipment and production of civilian products. It is also change of economic, social basis of production organization; assortment optimization, cost and product quality; continuous training and retraining; upgrading of technology, equipment, innovations implementation; changes in organizational structure of production and management. Additionally, this is incorporation of military-industrial complex into the intersectoral and international system [2].

A sad peculiarity of economic geography of Russia is that it is "built" around large enterprises, which are called forming. It was discovered that many cities live in close connection with military-industrial complex (MIC).

About 7-8 million workers and their families are involved in a production process in 9-10 major centers of defense production.

Concept of management involves two types of actions:

a) determining an optimal plan for a system development and operation;

b) immediate execution of a plan, i.e. transfer of a system to a state that is considered as optimal.

It is necessary to have a criterion for optimal decision making to make a management system rational. Balance is an ability of a system in absence of external influences to save its state indefinitely long period of time. Equilibrium state can be stable and unstable. Equilibrium is considered stable if a system, being derived from this state, is able to return to it, and otherwise unstable. Thus, sustainability is an ability of a system to return to equilibrium after it was out of this state.

The English term "sustainable" (supportive, long-term, sustainable, continuous) in the phrase "sustainable development", translated as "sustainable development" first appeared in the report "World Strategy of Nature Protection" (1980), represented by the International Union for Protection of Nature and Natural Resources. In this report, development is defined as "modification of a biosphere and use of human, financial, renewable and non-renewable natural resources to meet needs of people and improve "quality of life". In order for development to be sustainable, not only its economic aspects but also social and environmental factors should be taken into account. It is necessary to calculate all advantages and disadvantages of alternatives in both short and long term."

It is noted further that "nature conservation is such management by a human of biosphere resources which can bring additional sustainable profit to modern generation, and satisfaction of needs of future generations leaves no doubt."

Management as a process of structuring existence of a social ecological-economic object, at the same time, is a development management. Development is not only economic growth, i.e. the growth of income and production, but radical multidimensional change in human behavior, appearing in their education, culture, traditions, habits; social and institutional changes which are characterized by quality of life, freedom and alternative options. That is why this complex process can be considered only based on systemic, holistic thinking, considering the economy and the environment as a united system. 
Sustainable development is a multidimensional process mainly qualitative changes aimed to increase economic and social efficiency of social ecological-economic systems functioning and is achieved on the basis of systematic marketing management through principles of man saving, strategic thinking and updating.

Sustainable development implies creation of such socioeconomic system which would provide for long term not only a high standard of living, but also a high level of its quality, i.e. the growth of real incomes, educational levels, improving health care, etc. Scientists and experts, participants of the allRussian scientific-practical conference "Ecology and Economy - regional problems of transition to sustainable development" argued that, "it is not possible to say that a society is developed in case if capital (means of production, property, etc.) does not increase and environmental wealth is being depleted, or society reaches economic growth at the expense of other components of development. Indissolubility of economy and environment, their interdependence is one of the basic conditions of harmoniously developing society."

The main tasks of sustainable development of shipbuilding cluster are resource conservation (including energy efficiency), improving environmental conditions, economic growth, etc. These tasks are successfully resolved in a field of innovations, so innovations can be considered as a tool for sustainable development. Innovative development fits best goals of sustainable development of shipbuilding cluster, and innovative resource serves as an additional source of resistance. Therefore, at present, the only basis for sustainable development of shipbuilding cluster is a scientific-technical progress management [5].

Methodologically, concept of sustainable economic development is implementing a systematic approach to joint solution of economic and social objectives. A social platform of sustainable development concept is people-oriented, directed to protection of social and cultural environment stability. The task is not only of optimal management naturalresource potential, but also of the whole set of natural-social and cultural wealth of a civilization at a particular stage of world historical development. A system of indicators, linking totality of factors (economic, social, environmental, spiritual, etc.) that define dynamics of sustainable development of civilization, is highlighted.

The term "sustainable development" is most commonly defined as development that meets needs of the present, but does not jeopardize an ability of future generations to meet their own needs. Sustainable development is characterized by the following features. It:

does not cause additional costs for the next generations;

- minimizes negative externalities, and not only now, but also in the future;

provides a permanent simple or expanded reproduction of a productive capacity in the future;

Humanity lives on the interest from natural capital only, not spending this capital.

In general, sustainable development in time, taking into account the main parameters, can be represented as:

$$
F_{t}(L, K, P, I) \leq F_{(t+1)}(K, K, P, L),
$$

where $\mathrm{F}(\mathrm{L}, \mathrm{K}, \mathrm{P}, \mathrm{I})$ is a function of sustainable development; $\mathrm{L}$ - labor resources; K - artificially created (physical capital), means of production; $\mathrm{P}$-natural resources; I - institutional factor; $\mathrm{t}$-actual period; $\mathrm{t}+1$ is further period [6].

The whole economy with its current production processes and distribution of wealth, social system of society with its institutions and environment are elements of one system, and, therefore, all changes cannot be considered isolated. Developing together as a closed system, economic, social and natural subsystems must have feedback and respond to incoming signals. In particular, signals on occurrence of crisis phenomena in a natural subsystem need to be perceived by a social subsystem. Social subsystem should respond to these signals.

The ability of social subsystems to respond to incoming signals is mainly determined by institutional factors, i.e. cultural traditions of the society, religion, institutions of property, public and state institutions, an education level etc. Thus, a paradigm of the Economics of sustainable development fully meets principles of a system approach.

The main directions of Russia's transition to sustainable development are:

- elaboration of a legal basis for transition to sustainable development, including improvement of current legislation that defines, in particular, economic mechanisms of environmental management and environmental protection;

- development of a stimulation system for economic activity and establishing responsibility limits for economic results in which the biosphere is considred not only as a supplier of resources, but also as a foundation of life, which preservation should be a prerequisite for $t$ functioning of a socio-economic system and its individual elements.

Elaboration of a program and forecast document's system is the main task of public administration in transfer to sustainable development. These documents are:

$$
\begin{aligned}
& \text { - long-term state strategy; } \\
& \text { - long-term and medium-term forecasts, }
\end{aligned}
$$
including forecasts of changes in an environment and individual ecosystems by economic activities as integral components;

short-term forecasts and programs of sectorial and regional (territorial) and Federal levels.

One of the important conditions is a creation of an efficient interaction system "center - regions". Transition to sustainable development of the Russian Federation as a whole is possible only in case of sustainable development of all its regions, in particular, cities forming a specific region.

A problem of sustainable development of a city and a region is similar to a problem of sustainable development of society. At the city level, it is necessary to create such socioeconomic system that would ensure not only a high standard of living, but also a high level of life quality. In a socioeconomic system, it is necessary to consider also an implementation of ecological objectives, achievement of 
which should promote a concept of sustainable development, such as ensuring a stability of biological and physical systems, an ability of an ecosystem to repair itself and adapt to environmental changes.

Severodvinsk is a factory town actually fully closed on the Center of nuclear shipbuilding. Prestige of the military industry branches, relatively acceptable social condition of the city contributed over many years to the intensive inflow of labor force. More than $60 \%$ of employed population of the city work in defense industry [8].

The largest consumers of human, material, energy, financial resources are enterprises of Severodvinsk. Severodvinsk shipbuilding cluster focuses on production and repair of submarines for the Navy. In the early 1990-ies, it has the status of the Russian State Nuclear Shipbuilding Center (RSNSC). Production capacity of these companies is able to process tens of thousands of tons of metal per year in various wares. A wide range of equipment allows producing a very large range of engineering products, including high-tech, through application of scientific and technological progress.

Innovative processes are manifold and differ by their nature; therefore, forms of their organization, scope and methods of influence on innovative activity of such enterprises are also various. Enterprises which pioneered efficient innovations, are able to reduce production costs and, therefore, cost of goods sold. It strengthens their positions in a competition. Start-up of companies supporting development of innovative activities plays an important role in a formation of an innovative basis for sustainable development of the shipbuilding cluster of Arkhangelsk region [4].

The roughest errors in governmental economic policy and slowness in management decisions of top-managers of local defense enterprises in the 90-ies have led to decrease in production volumes to the level below $\mathrm{t}$ critical and brain drain to other industries and regions. These years are estimated as severely depressed. This is largely due to a specificity of shipbuilding production: duration of a production cycle, a wide range of materials and components, dependence on many suppliers, complexity of the market structure for marine products.

It must be remembered that establishment of a favorable investment environment is associated with risks minimization in the regions and in the whole country. This will increase a mobility of capital and labor force, stabilize the socioeconomic situation, increase investment protection. Another element of a transition to an innovative way of development is tan innovative strategy formulation. It includes priorities of technological development, which define main directions of innovative management development, allowing effective use of human resources in innovation, upgrading legislative framework of an innovative sphere, primarily in a field of taxation; restructuring a scientific sphere with release of the innovation sector and search for the most effective completed research projects that can be implemented in effective and innovative projects.

Solution of this problem is, firstly, associated with a necessity to form favorable conditions for stability of structural transformation. Secondly, it is associated with adequate use of economic levers which determine functioning and regulation of innovative-investment sector in activities of both public and private companies.

Thus, innovation as a process is supported by investment and relevant institutions, without which a mechanism of their realization just will not start, new ideas and technical development will remain only in minds of their designers without being turned into innovations [3].

Managing a development of the shipbuilding cluster and single-industry towns, formation of innovative potential of the region should be based on a concept of sustainable development and a role of higher education. Benchmarks or normative indicators which would allow one to regulate and to monitor this process should be selected. These guidelines should represent a range of economic, social and environmental performance; perhaps it may be a quantitative description of factors of sustainable development and innovative potential. It is obviously that among them, the leading indicators are:

- index of gross regional product;

- index of physical volume of industrial production;

- consumer price index;

- coefficient of income differentiation of the population;

- natural increase (decrease ) of the population;

- infant mortality rate;

- employment of population;

- index of human development;

- investments in environmental protection and rational use of natural resources.

\section{References}

[1] Electronic Encyclopedia. The Knowledge Fund of the University. URL: http://lomonosov-fund.ru/enc/ru/encyclopedia:0131515 (accessed: 10.07.2017)

[2] Database Cluster Projects in the Subjects of the Russian Federation, Materials of the Website of the Ministry of Economic Development of the Russian Federation http://www.economy.gov.ru/minec/activity/sections/ innovations /development/doc1248781849803 (accessed: 10.07.2017)

[3] Granberg A. Strategy of the Social-Economic Development of Russia: from Ideas to Realization, Economic Issues, Vol.9, 2001.

[4] I. Danilova, Problems of the Higher Professional Education Modernization URL: http://www.superinf.ru / view helpstud.php?id= (accessed: 10.07.2017)

[5] A. Zavyalov, A. Goev, Problems of City Forming Enterprises of Defense Industry Restructurization, The Conversion in Mechanical Engineering, Vol.4, 1997.

[6] Yu. V. Yakovets, Innovations: Theory, Mechanism, State Regulation, Moscow, RAGS, 2000.

[7] Innovative Russia 2020, URL: http://innovation.gov.ru/ taxonomy/ term/586 (accessed: 10.07.2017)

[8] E. Osipova, "Sustainable Development of the Regional Shipbuilding Clusrer as a Center of Innovative Economy," Economy and Entrepreneurship, Vol. 5-1, pp. 82, 2017.

[9] Official website of the Government of the Arkhangelsk region URL: http://www.dvinaland.ru (accessed: 10.07.2017)

[10] Official site of the Northern (Arctic) Federal University URL: http://www.narfu.ru (accessed: 10.07.2017) 
[11] Priorities of Innovative Society: foreign experience. Finland, Ireland, Canada, South Korea. An analytical review, Information-Methodical Bulletin, Tver InnoCenter, Vol. 2, 2011.

[12] Strategy for Socio-Economic Development of Arkhangelsk Region until 2030 http://www.arhadm.gov.ru/economy/strategy (accessed: 10.07. 2017)
[13] E. Shirikhinam "Role of the Higher School in Regional Innovative Potential Forming," Organizational-economic mechanism of management of advanced development of regions, 2016. 